\title{
Tandem Mass Spectrometric Strategies for Determination of Sulfation Positions and Uronic Acid Epimerization in Chondroitin Sulfate Oligosaccharides
}

\author{
Joseph Zaia, Xue-Qing Li, Shiu-Yung Chan, and Catherine E. Costello \\ Department of Biochemistry, Boston University School of Medicine, Boston, Massachusetts, USA
}

Chondroitin sulfate (CS) is a glycosaminoglycan consisting of repeating (HexA-GalNAc sulfate) disaccharides, the functions of which depend on patterns of sulfation and uronic acid epimerization. The correlation of biological activities with structure requires a strategy to determine the sequences of CS oligosaccharides without the need for total isolation. Tandem mass spectrometry has enabled the development of proteomics, based on CID fragmentation of ions produced from complex mixtures of proteolytic peptides, and has the potential for rapid sequencing of CS and other glycosaminoglycan classes. The most challenging aspects of CS sequencing are to distinguish GalNAc residues sulfated at the 4- versus the 6-position and uronic acid epimers. This work describes the utility of (1) reducing terminal derivatives and (2) control of precursor ion charge state for tandem mass spectrometric strategies for determining GalNAc sulfation positional isomers of CS. The capability of tandem MS to differentiate uronic acid epimers is also shown, providing evidence that complete or nearly complete information on CS covalent structure may be obtained using tandem MS. (J Am Soc Mass Spectrom 2003, 14, 1270-1281) @ 2003 American Society for Mass Spectrometry

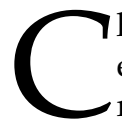
hondroitin sulfate (CS) is a glycosaminoglycan expressed on cell surfaces and in extracellular matrices, composed of repeating disaccharide units of [GlcA(1-3)GalNAc(1-4)] bound through a xylosyl linker to Ser residues of a proteoglycan core protein. Proteoglycans modified with CS chains include the lecticans (aggrecan, versican, neurocan, also known as hyalectins) [1], some members of the small leucine rich proteoglycans (SLRPS, decorin and biglycan) [2], and cell surface proteoglycans (syndecans) [3]. Most of the disaccharide units are sulfated at either the 4- or 6-position of GalNAc residues, with a small percent modified at both positions. In dermatan sulfate, a large percent of the uronic acid residues are epimerized to IdoA and may be sulfated at the 2-position [4]. CS/DS chains are polydisperse with respect to both length and composition and average masses have been reported from 50 to $140 \mathrm{kDa}$, varying markedly in different tissues and disease contexts. The extended CS chains consist of domains of high and low IdoA content, as shown from polyacrylamide gel electrophoresis (PAGE) [5] and high performance liquid chromatography (HPLC) [6]. Several studies have shown that CS/DS

Published online September 11, 2003

Address reprint requests to Dr. J. Zaia, Department of Biochemistry, Boston University School of Medicine, 715 Albany St., R-806, Boston, MA 021182526. E-mail: jzaia@bu.edu domains bind proteins and potentiate their biological activities [7-10].

Information on fine structure has been generated by enzymatic depolymerization of CS followed by fluorescent tagging and chromatographic or electrophoretic separation of the disaccharide products [11-13]. The size of corneal CS chains is known to decrease as a result of macular corneal dystrophy, the content of disulfated disaccharides to increase, and the overall chain concentration to increase [14]. The sulfation pattern of CS chains bound to cartilage aggrecan has been shown to change during development, with a mixture of 4- and 6-sulfated GalNAc residues present in juveniles and almost exclusively 6-sulfated such residues in adults [15-17]. The non-reducing terminal composition of CS chains has also been observed to vary with maturation and the onset of osteoarthritis [13, 18, 19], showing that disease-specific changes to CS structure are found in specific domains.

Due to the lack of analytical techniques, little is known about the extended sequences of CS domains with respect to sulfation and uronic acid epimerization, how these structures interact with binding proteins, and how they vary with development and disease onset. Although, like peptides, CS chains may be enzymatically depolymerized to oligomers, tandem MS has not been widely applied for sequence determination. Investigations using FAB MS showed that quasimolecular 
ions were produced for CS oligosaccharides only in very low abundances, accompanied by more abundant ions resulting from fragmentation of sulfate groups [20, 21]. Although FAB tandem MS has been used to study CS oligosaccharides up to tetramers size, the singly charged nature of these ions resulted in abundant fragments resulting from loss of sulfate groups [22]. Intact molecular ions could, however, be produced using electrospray ionization (ESI) in the negative mode, and tandem MS has been applied to the CS oligosaccharide ions so generated $[23,24]$. Because CS disaccharides sulfated at the 4- or 6-position of the GalNAc residue, respectively, produce distinct CID product ion patterns [25-27], quantitative measurements based on ion abundances provide useful information on the global domain organization of CS chains [28]. It has also been shown that the information content of tandem mass spectra generated from CS oligosaccharides is strongly dependent on the charge state of the precursor ion [24]. Further, it was shown that the relative abundances of the individual glycosidic bond cleavage ions formed reflect the position of GalNAc sulfation [23].

The present work addresses two analytical challenges in the tandem mass spectrometric analysis of CS oligosaccharides. The first challenge is that monoisotopic peaks for CS oligomers of different length are observed at the same $m / z$ value (458), resulting in the observation of overlapping isotopic clusters. The fragmentation characteristics of $m / z 458$ are favorable, however, because all sulfate groups are charged, and therefore do not undergo fragmentation at collision energies that are sufficient for cleavage of glycosidic bonds. To address this problem, the use of reducing terminal derivatives is explored in order to eliminate the problem of different $\Delta$-unsaturated CS oligomers producing the same $m / z$ value while preserving the favorable charge state and attaching a chromophore to facilitate detection. The utility of these derivatives is compared with that of CID of higher charge states for underivatized $\Delta$-unsaturated CS oligosaccharides. These charge states, which have unique $\mathrm{m} / \mathrm{z}$ values for different oligomer lengths, are evaluated with respect to information content of the product ion mass spectra. The second challenge is in the differentiation of uronic acid epimers. It is shown that the abundances of specific CID product ions generated from CS oligosaccharides vary depending on uronic acid epimerization state for CS oligosaccharides.

\section{Methods}

\section{Preparation of Saturated Chondroitin Sulfate Oligosaccharides}

CSA or CSC (Seikagaku/Associates of Cape Cod, Falmouth, MA) was digested with testicular hyaluronidase (Sigma Chemical Co., St. Louis, MO) and fractionated using high performance size exclusion chromatography as described [27]. Briefly, the column (Superdex Peptide 3.2/30, Amersham Biosciences, Piscataway, NJ) was equilibrated in $30 \%$ methanol, $0.1 \mathrm{M}$ ammonium acetate solution at $100 \mu \mathrm{L} / \mathrm{min}$ and the oligosaccharide mixture (2-10 $\mu \mathrm{L})$ injected with detection at $214 \mathrm{~nm}$.

\section{Preparation of $\Delta$-Unsaturated Chondroitin Sulfate Saccharides}

CSA or CSC $(10 \mu \mathrm{L}, 10 \mathrm{mg} / \mathrm{mL})$ was mixed with water $(10 \mu \mathrm{L})$, tris- $\mathrm{HCl}$ buffer $(2 \mu \mathrm{L}, 1 \mathrm{M}, \mathrm{pH} 7.4)$, ammonium acetate $(1 \mu \mathrm{L}, 1 \mathrm{M})$ and chondroitinase ACI $(5 \mu \mathrm{L}, 5$ $\mathrm{mU} / \mu \mathrm{L}$, Seikagaku), digested for $10 \mathrm{~min}$ at $37^{\circ} \mathrm{C}$ and boiled for $1 \mathrm{~min}$. An aliquot $(10 \mu \mathrm{L})$ was then fractionated using high performance size exclusion chromatography as above, except with detection at $232 \mathrm{~nm}$. CSB was digested with chondroitinase $\mathrm{ABC}(5 \mu \mathrm{L}, 5 \mathrm{mU} /$ $\mu \mathrm{L})$ using the same conditions and purification as above.

\section{2-Aminopyridine Derivatives (AP)}

Unreduced AP derivatives were prepared according to a published procedure [29]. CS chondroitinase digests were desalted, dried, and dissolved in neutralized aqueous AP solution $(20 \mu \mathrm{L}, 89 \mu \mathrm{M})$ and incubated overnight at $65{ }^{\circ} \mathrm{C}$. The digest mixture was then fractionated using high performance size exclusion chromatography as above.

\section{2-Aminobenzamide Derivatives (2AB)}

Unreduced $2 \mathrm{AB}$ derivatives were prepared by dissolving desalted and dried CS oligosaccharides $(10 \mu \mathrm{g})$ with 2AB solution (5-10 $\mu \mathrm{L}, 2.5 \mathrm{M}$ in 1:1 methanol:acetic acid) and incubating at $65{ }^{\circ} \mathrm{C}$ for $2 \mathrm{~h}$. Derivatized oligosaccharides were fractionated using high performance size exclusion chromatography as above.

\section{3,5-Dimethylpyrazole Derivatives (PZ)}

Using a modification of a published method [30], desalted and dried CS oligosaccharides were dissolved in water $(20 \mu \mathrm{L})$, hydrazine hydrate $(20 \mu \mathrm{L})$ was added and the mixture incubated at $37{ }^{\circ} \mathrm{C}$ for $35 \mathrm{~min}$. The mixture was dried using a centrifugal evaporator, dissolved in methanol $(100 \mu \mathrm{L})$, and dried again before adding methanol $(30 \mu \mathrm{L})$, water $(10 \mu \mathrm{L})$, and acetylacetone $(5 \mu \mathrm{L})$. After vortexing, the mixture was incubated at $37^{\circ} \mathrm{C}$ for $40 \mathrm{~min}$, dried, dissolved in methanol $(100 \mu \mathrm{L})$ and dried again. Oligosaccharides were analyzed directly by nano ESI MS.

\section{Electrospray Quadrupole Orthogonal Time-of- Flight Mass Spectrometry}

Mass spectra were acquired in the negative ion mode using an Applied Biosystems/MDS-Sciex API QSTAR 
Pulsar-i quadrupole orthogonal time-of-flight (Q-oTOF) mass spectrometer (Framingham, MA). Samples were dissolved in water and diluted in sufficient volume of $30 \%$ methanol to achieve a $1 \mathrm{pmol} / \mu \mathrm{L}$ solution. In later experiments, the addition of $0.03 \%$ ammonium hydroxide was found to produce a more stable spray. Aliquots $(3 \mu \mathrm{L})$ were infused into the mass spectrometer source using 1-2 $\mu \mathrm{m}$ orifice nanospray [31] tips pulled from thin-wall borosilicate glass capillaries (1.2 mm o.d., 0.90 $\mathrm{mm}$ i.d.; World Precision Instruments, Sarasota, FL) using a Sutter Instrument P 80/PC micropipette puller (San Rafael, CA). Steady ion signal was typically observed using a needle potential of $-1000 \mathrm{~V}$ and all spectra were calibrated externally. For CID, the collision energy was set so that the precursor ion remained abundant while observing product ions.

\section{Quadrupole Ion Trap Mass Spectrometry}

Negative ionization nano-electrospray mass spectra were acquired using a Bruker Daltonics (Billerica, MA) Esquire 3000 instrument equipped with a Picoview source. Nanospray needles were pulled as above and ion source conditions were set so as to desolvate the ions without causing losses of $\mathrm{SO}_{3}$ (skimmer 1-10 V, capillary exit offset $-20 \mathrm{~V}$ ). The nitrogen dry gas was flowed at $1 \mathrm{~L} / \mathrm{min}$ and the drying temperature was 150 ${ }^{\circ} \mathrm{C}$. Scans were acquired at $13,000 \mathrm{u} / \mathrm{s}$ and the target was set to 18,000 ions with a maximum accumulation time of $50 \mathrm{~ms}$. Oligosaccharides were dissolved at 5 $\mathrm{pmol} / \mu \mathrm{L}$ in $30 \%$ methanol, $0.03 \%$ ammonium hydroxide, and $3-\mu \mathrm{L}$ portions were sprayed by grounding the solution and setting the orifice potential to $600-800 \mathrm{~V}$ positive relative to the solution. For CID, 3-u windows were selected and excited for $40 \mathrm{~ms}$. The collision amplitude was adjusted so that fragment ions were produced without obliterating the precursor ion.

\section{Results and Discussion}

The most abundant charge states in ESI mass spectra of CS oligosaccharides typically correspond to one charge per sulfate group [23, 24]. For oligosaccharides generated by chondroitinase enzymes, which cleave GalNAcHexA glycosidic bonds by an eliminative mechanism to produce a $\Delta$-unsaturated HexA residue at the new non-reducing terminus, the monoisotopic peak at $\mathrm{m} / \mathrm{z}$ 458 is isobaric for oligomers of different lengths, resulting in overlapping isotopic patterns, as shown in Figure 1. The CS oligomers are identified according to their composition as $[\Delta(\mathrm{X}, \mathrm{Y}, \mathrm{Z})-\mathrm{nH}]^{\mathrm{n}-}$, where $\mathrm{X}=$ the number of HexA residues (including the $\Delta$-unsaturated residue), $Y=$ the number of GalNAc residues, and $Z=$ the number of sulfate groups. Although saturated CS oligosaccharides produced by testicular hyaluronidase, an enzyme acting by a hydrolytic mechanism, form unique $\mathrm{m} / \mathrm{z}$ values for the most abundant ions from different oligomer lengths, transglycosylase reactions [32, 33] limit the usefulness of this enzyme for sequence analy-

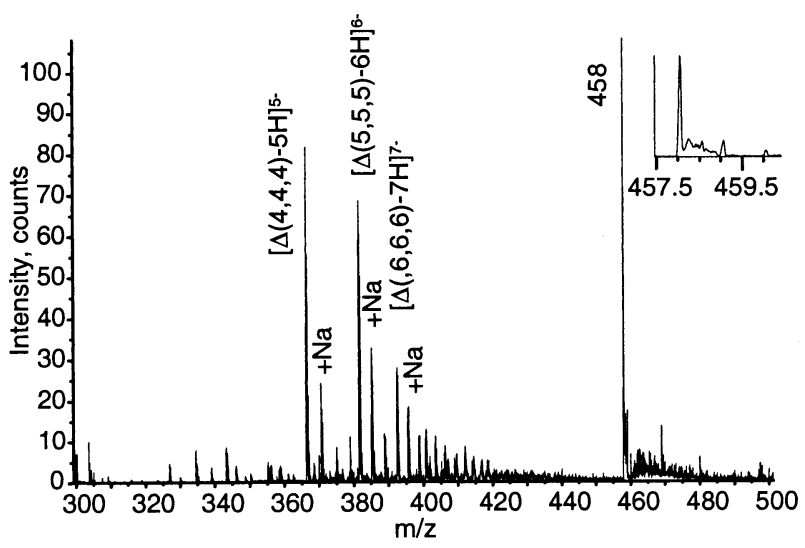

Figure 1. Negative ESI Q-oTOF mass spectrum of a mixture of CS oligosaccharides. The compositions and charge states of CS oligosaccharide ions are given as $[\Delta(X, Y, Z)-n H]^{n-}$, where $X=$ HexA residues, including the $\Delta$-unsaturated residue, $Y=$ GalNAc residues, and $Z=$ sulfate groups. The isotopic envelope for $\mathrm{m} / \mathrm{z}$ 458 is shown in the inset.

sis. There are two ways to address overlapping charge state problem for $\Delta$-unsaturated CS oligosaccharides: (1) To use reducing terminal derivatives, thereby forming ions with unique $\mathrm{m} / \mathrm{z}$ values and (2) to analyze higher charge states for underivatized $\Delta$-unsaturated CS oligosaccharides, for which $\mathrm{m} / \mathrm{z}$ values are unique. Results using both approaches are shown in this work.

Reductive amination has been widely used for attachment of chromophores to the reducing end of carbohydrates to facilitate chromatographic separation and quantitation prior to MS [34-38]. Reaction of the oligosaccharide with an amine has most often been followed by reduction, producing an open ring structure at the former reducing end. Tandem mass spectra of reduced forms of CS delta $(4,5)$-unsaturated disaccharides $\left[\Delta \mathrm{HexA}(1,3) \mathrm{GalNAcSO}_{3}\right], \Delta \mathrm{Di} 4 \mathrm{~S}$ and $\Delta \mathrm{Di} 6 \mathrm{~S}$, are not distinguishable, showing that determination of the position of GalNAc sulfation requires a closed ring reducing end structure [24]. Unreduced alkylamine derivatives of monosaccharides are known to exist as close ringed glycosylamines [39] and have been used to facilitate chromatographic and MS analysis of saccharides [29, 40, 41]. Because the mass spectra of the glycosylamines produce more information on linkage than do those of corresponding reduced derivatives, the CID product ion mass spectra of glycosylamine derivatives of CS GAGs were investigated. The glycosylamine derivatives provide clear advantages and allow for the analysis of ions that are not amenable in their underivatized forms.

Aminopyridine (AP) and 2-aminobenzamide (2AB) are commonly used derivatives, in both reductive amination and non-reducing procedures, for attaching chromophores to oligosaccharides to facilitate their chromatographic separation and detection in conjunction with MS [34, 35, 38, 42]. 3,5-Dimethylpyrazole (PZ) [30], although a weak chromophore, is also attractive because derivatization is accomplished using volatile 

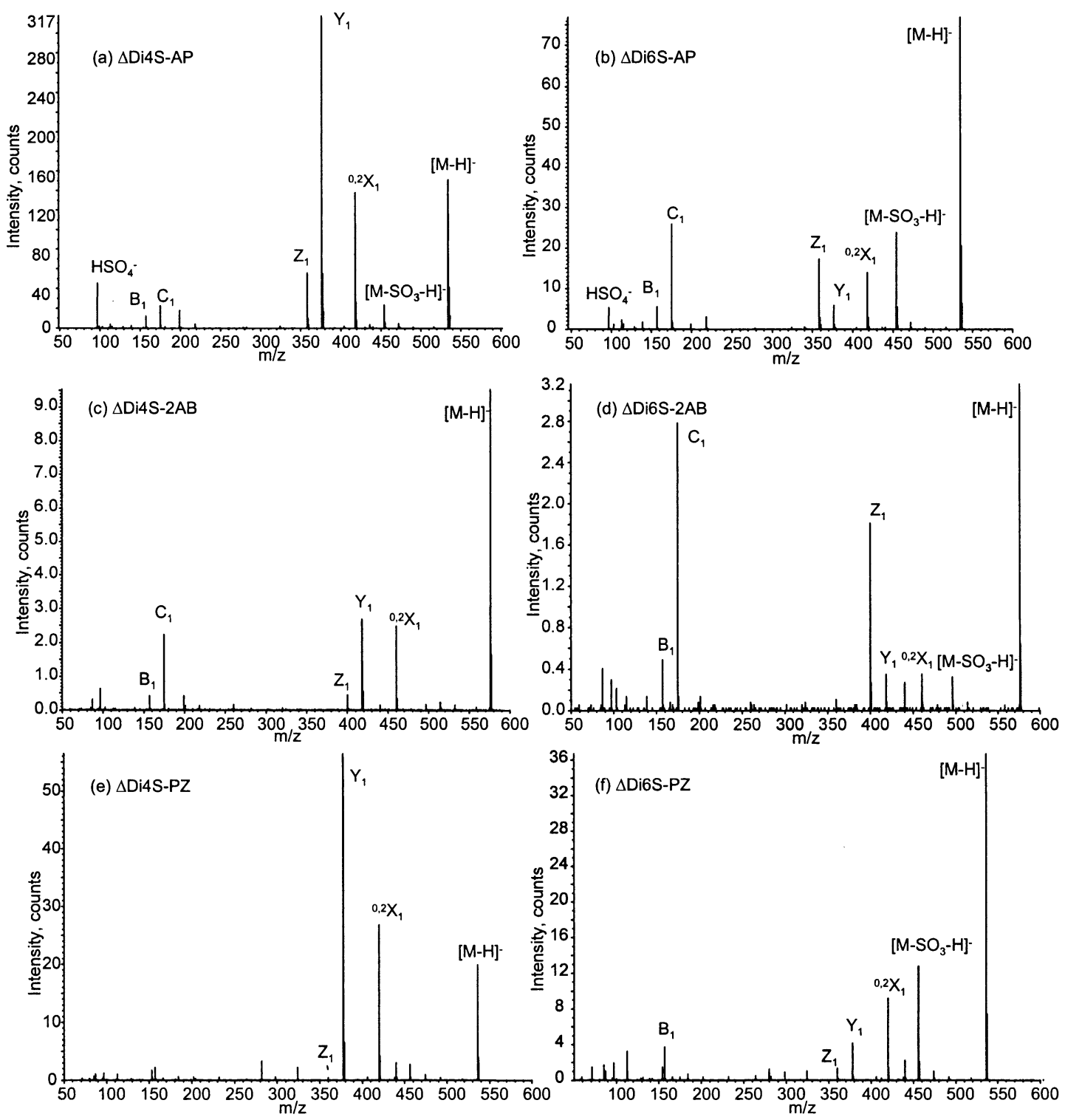

(g)

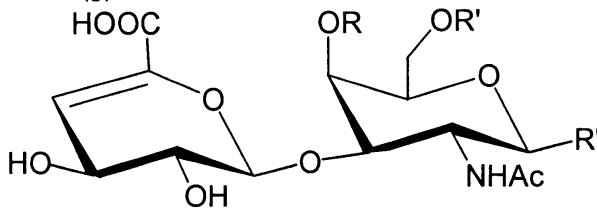

$\Delta_{4,5}$ Unsaturated CS disaccharides

$\triangle \mathrm{Di} i \mathrm{~S}, \mathrm{R}=\mathrm{SO}_{3} \mathrm{H}, \mathrm{R}^{\prime}=\mathrm{H}$

$\Delta \mathrm{Di}$ i6S, $\mathrm{R}=\mathrm{H}, \mathrm{R}^{\prime}=\mathrm{SO}_{3} \mathrm{H}$ (h)

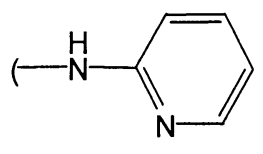<smiles>CNc1ccccc1CN</smiles><smiles>Cc1cc(C)n(C)n1</smiles>

2-aminopyridine 2-aminobenzamide 3,5-dimethylpyrazole AP $2 A B$

Figure 2. Q-oTOF tandem mass spectra of the $\Delta$-unsaturated CS disaccharide derivatives, (a, b) AP; $(\mathbf{c}, \mathbf{d}) 2 \mathrm{AB} ;(\mathbf{e}, \mathbf{f}) \mathrm{PZ}$, all at $-30 \mathrm{~V}$ collision energy. The structures of the disaccharides are shown in (g) and the derivatives in (h).

reagents, with no reducing step, and with no sample cleanup necessary. The tandem mass spectra of the AP derivative of $\Delta$ Di4S (Figure 2a), the AP derivative of $\triangle \mathrm{Di6S}$ (Figure $2 \mathrm{~b}$ ), the $2 \mathrm{AB}$ derivative of $\triangle \mathrm{Di} 4 \mathrm{~S}$ (Figure $2 \mathrm{c}$ ), the $2 \mathrm{AB}$ derivative of $\triangle \mathrm{Di} 6 \mathrm{~S}$ (Figure $2 \mathrm{~d}$ ), the PZ derivative of $\Delta$ Di4S (Figure 2e), and the PZ derivative of 
$\Delta$ Di6S (Figure 2f) are shown. Abundant $Y_{1}$, and ${ }^{0,2} X_{1}$ ions are observed in the spectrum of the $\Delta \mathrm{Di} 4 \mathrm{~S}-\mathrm{AP}$, in a pattern similar to that observed for underivatized $\Delta$ Di4S [23]. The tandem mass spectrum of $\Delta$ Di6S-AP is characterized by abundant ions corresponding to $Z_{1}$, ${ }^{0,2} \mathrm{X}_{1}$, and $\left[\mathrm{M}-\mathrm{SO}_{3}-\mathrm{H}\right]^{-}$. The observation of ion abundances corresponding to $Y_{1}>Z_{1}$ for $\Delta$ Di4S-AP and $Z_{1}>$ $Y_{1}$ for $\Delta$ Di6S-AP are similar to those of underivatized disaccharides. A similar pattern of glycosidic bond cleavage ion abundances is observed in the spectra of $\triangle \mathrm{Di} 4 \mathrm{~S}-2 \mathrm{AB}$ (Figure $2 \mathrm{c}$ ) and $\triangle \mathrm{Di}$ i6S-2AB (Figure $2 \mathrm{~d}$ ) and the $\left[\mathrm{M}-\mathrm{SO}_{3}-\mathrm{H}\right]^{-}$ions are in lower abundances. These results are consistent with a closed ring glycosylamine structure for the GalNAc residue when derivatized with $\mathrm{AP}$ or $2 \mathrm{AB}$. Glycosidic bond cleavage thus produces $Y_{1}$ and $Z_{1}$ ion abundances similar to those observed in spectra of the underivatized disaccharide.

The product ion profile generated from $\triangle \mathrm{Di} 4 \mathrm{~S}-\mathrm{PZ}$ (Figure 2e) is qualitatively similar to those of the $\triangle$ Di4S-AP (Figure 2a) and $\triangle$ Di4S-2AB (Figure 2c) in that an abundant $Y_{1}$ ion is observed with that corresponding to $Z_{1}$ in very low abundance. The $\triangle$ Di6S-PZ CID profile, however, shows abundant $\left[\mathrm{M}-\mathrm{SO}_{3}-\mathrm{H}\right]^{-}$and ${ }^{0,2} \mathrm{X}_{1}$ ion with $Y_{1}$ in higher abundance than $Z_{1}$, consistent with the conclusion that an open-ring structure has been formed by the derivative. It has been demonstrated that CID of open-ring CS disaccharides produce similar CID patterns regardless of the GalNAc sulfation position [24].

For the purpose of evaluating the product ion patterns of glycosylalkylamine derivatives of CS oligosaccharides, two series of derivatives were used. Saturated CS oligosaccharides, produced by testicular hyaluronidase, were derivatized using $\mathrm{AP}$ and $\Delta$-unsaturated oligosaccharides were derivatized using $2-\mathrm{AB}$. The derivatives were chosen so that CID spectra of CS hexamers differing in structure from both the reducing and non-reducing ends could be compared. Because the structures differ on both ends, the masses of all glycosidic bond fragment ions will be unique. Ions produced from internal bond cleavages will be thus be clearly identified because they will be observed to have the same $\mathrm{m} / \mathrm{z}$ values in product ion mass spectra acquired from both derivatives. Having identified internal fragment ions in CID profiles, it is possible to optimize conditions to minimize the abundances of these undesirable ions. The ion at $m / z 458$ in Figure 3 is an internal fragment ion, the abundance of which may be minimized by using a collision energy at which the abundance of the precursor ion remains high.

Figure 3 shows tandem mass spectra of CSA $[(3,3,3) \mathrm{AP}-3 \mathrm{H}]^{3-}$ and CSA $[\Delta(3,3,3) 2 \mathrm{AB}-3 \mathrm{H}]^{3-}$ acquired at $-20 \mathrm{~V}$ collision energy. Both spectra are characterized by abundant ions corresponding to $\mathrm{Y}_{1}^{1-}, \mathrm{Y}_{3}^{2-}, \mathrm{Y}_{5}^{3-}$, $\mathrm{B}_{3}^{1-}$, and $\mathrm{B}_{5}^{2-}$. As with underivatized oligosaccharides with the same charge state, odd numbered $B_{m}$ and $Y_{n}$ ions are produced from cleavages to the non-reducing side of GalNAc residues. This pattern is unusual in the context of glycan CID fragmentation because abundant product ions are usually formed to the reducing side of

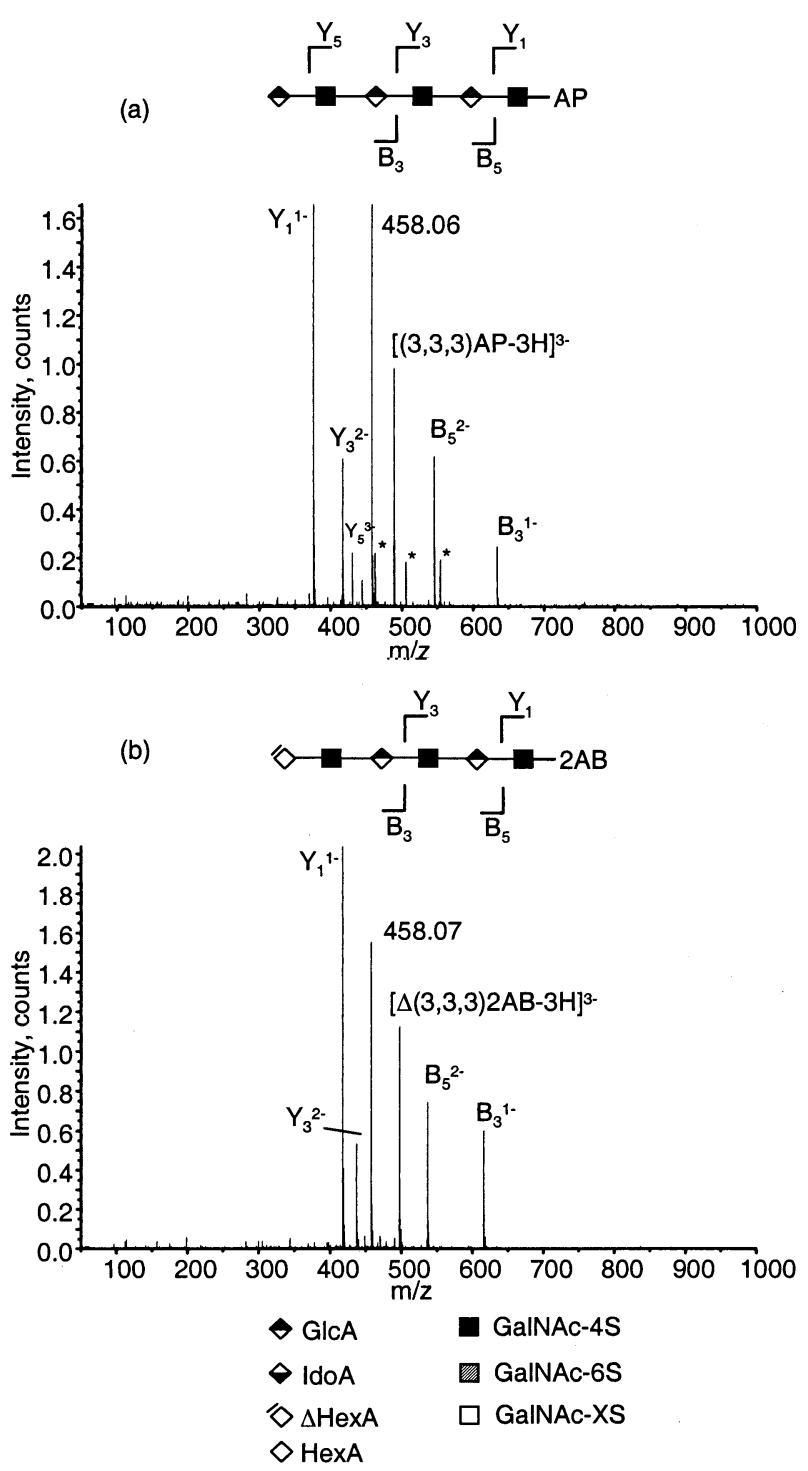

Figure 3. Q-oTOF tandem mass spectra of (a) CSA $[(3,3,3) \mathrm{AP}-$ $3 \mathrm{H}] 3-$ and $(\mathbf{b}) \mathrm{CSA}[\Delta(3,3,3) 2 \mathrm{AB}-3 \mathrm{H}] 3-$ acquired at $-20 \mathrm{~V}$ collision energy. Ions produced from losses of $\mathrm{SO}_{3}$ are labeled with an asterisk.

HexNAc residues [43], a phenomenon observed for protonated, deprotonated, and alkali-adducted ions [44, 45]. It appears that mobile protons (or metal cations) associate preferentially with the HexNAc amide nitrogen atom, and destabilize the glycosidic bond to the reducing side. Cleaving this bond is thus facile and the corresponding product ions are abundant. CS oligosaccharide ions corresponding to $[\Delta(3,3,3)-2 \mathrm{H}]^{2-}$, in which one of the sulfate groups remains protonated, fragment to form glycosidic bond product ions that follow this pattern from cleavage to the reducing side of GalNAc residues. The ions corresponding to $[\Delta(3,3,3)-3 \mathrm{H}]^{3-}[23$, $24]$ and those shown in Figure 3, fragment to the non-reducing side of GalNAc residues, indicating that this is the most labile bond in the ion. It is speculated that, in circumstances where there are no mobile protons, the uronic acid $\mathrm{COOH}$ group interacts with the 
glycosidic oxygen, making it the most labile bond in the ion and that this interaction is masked when mobile protons are present.

Although AP and $2 \mathrm{AB}$ are both useful as chromophoric derivatives, their CID properties are subtly different. The product ion mass spectrum generated by CID of CSA $\Delta[(3,3,3)]^{3-}$ (see Figure 8 ) is similar to that of the $2 \mathrm{AB}$ derivative (Figure $3 \mathrm{~b}$ ) in that glycosidic bond cleavage ions are produced without losses of $\mathrm{SO}_{3}$. The $[(3,3,3) \mathrm{AP}]^{3-}$ ion (Figure $\left.3 \mathrm{a}\right)$, produce abundant fragments corresponding to $\left(\mathrm{B}_{5}-\mathrm{SO}_{3}\right)^{2-}$ at $\mathrm{m} / \mathrm{z} 506.09$ and $\left(\mathrm{B}_{3}-\mathrm{SO}_{3}\right)^{1-}$ at $m / z 554.15$. It is possible that the interaction between the pyridine ring of the AP derivative and a neighboring carboxylic acid group makes a proton mobile and results in the destabilization of a sulfate group. For practical purposes, the absence of $\mathrm{SO}_{3}$ losses from $\mathrm{B}_{\mathrm{m}}$ ions for the $2 \mathrm{AB}$ to make it the preferred derivative for attaching a chromophore to CS oligosaccharides followed by MS.

Tandem mass spectra were acquired on CS oligosaccharides derived from CSA (4-sulfated) and CSC (6sulfated) corresponding to $[\Delta(2,2,2) 2 \mathrm{AB}-2 \mathrm{H}]^{2-}$, $[\Delta(3,3,3) 2 \mathrm{AB}-3 \mathrm{H}]^{3-}, \quad[\Delta(4,4,4) 2 \mathrm{AB}-4 \mathrm{H}]^{4-}, \quad$ and $[\Delta(5,5,5) 2 \mathrm{AB}-5 \mathrm{H}]^{5-}$ and Figure 4 compares the percent total product ion abundances for the two sulfation isomers. For each oligomer size, the abundance of the $\mathrm{Y}_{1}^{1-}$ ion is greater for oligosaccharides derived from CSA than for CSC, a trend observed for Figure $4 \mathrm{~b}$ $[\Delta(3,3,3) 2 \mathrm{AB}-3 \mathrm{H}]^{3-}$, Figure $4 \mathrm{c}[\Delta(4,4,4) 2 \mathrm{AB}-4 \mathrm{H}]^{4-}$, and Figure $4 \mathrm{~d}[\Delta(5,5,5) 2 \mathrm{AB}]^{5-}$. Interestingly, when underivatized oligosaccharides are reduced using $\mathrm{NaBD}_{4}$, the abundances of the $\mathrm{Y}_{1}^{1-}$ ions are the same between structures derived respectively from CSA and CSC [23]. This demonstrates that the $\mathrm{Y}_{1}^{1-}$ ion abundance is influenced by the position of sulfation at the reducing terminus of the GalNAc but only for unreduced/closed ring structures. The $\mathrm{B}_{1}^{1-}$ ion for all four oligomers was observed in low abundances, indicating that cleavage of the bond adjacent to the non-reducing terminal $\Delta \mathrm{HexA}$ residue is not favorable. The abundances of $Y_{n}$ ions, other than $\mathrm{Y}_{1}$, do not follow a trend for oligosaccharides derived from CSA versus CSC for the charge states in which $z=$ number of sulfate groups.

Cleavages of the glycosidic bond adjacent to the reducing terminus produce $B_{n}$ ions, the high abundances of which indicate that subsequent fragmentation does not occur under the conditions used. The higher relative abundances of $\mathrm{B}_{\mathrm{n}}$ ion produced from $\Delta$-unsaturated oligosaccharides derived from CSA, compared with those from CSC, indicate that glycosidic bonds to the non-reducing side of 4-sulfated GalNAc residues are more labile than those to the same side of 6-sulfated residues. These results imply that the abundance of each $B_{n}$ ion is useful for determining the position of sulfation of a specific GalNAc residue.

Tandem mass spectra of CSA and CSC derived $[\Delta(5,5,5) \mathrm{PZ}-5 \mathrm{H}]^{5-}$ are shown in Figure 5 . The spectra are characterized by $\mathrm{B}_{3}^{1-}, \mathrm{B}_{5}^{2-}, \mathrm{B}_{7}^{3-}, \mathrm{B}_{9}^{4-}$, and $\mathrm{Y}_{1}^{1-}, \mathrm{Y}_{3}^{2-}$, $\mathrm{Y}_{5}^{3-}, \mathrm{Y}_{7}^{4-}$ ions. Ions corresponding to loss of sulfate from
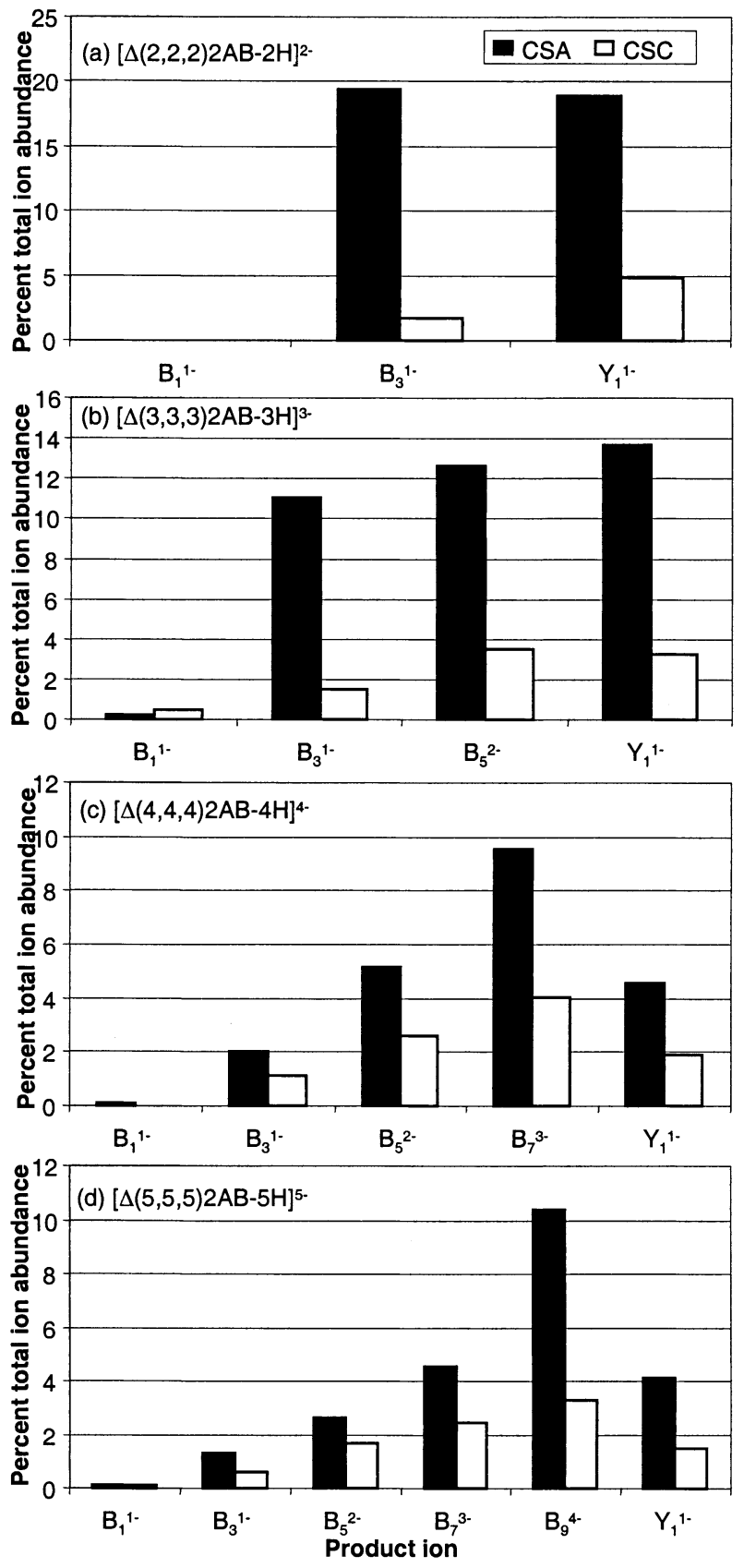

Figure 4. Comparison of percent total ion abundances for $B_{m}$ ions observed in Q-oTOF tandem mass spectra of 2AB-derivatized oligosaccharides derived from CSA and CSC, respectively. (a) CSA $[\Delta(2,2,2) 2 \mathrm{AB}-2 \mathrm{H}]^{2-} \mathrm{CE}-20 \mathrm{~V},\left(\right.$ b) $[\Delta(3,3,3) 2 \mathrm{AB}-3 \mathrm{H}]^{3-} \mathrm{CE}$ $-20 \mathrm{~V}$, (c) $[\Delta(4,4,4) 2 \mathrm{AB}-4 \mathrm{H}]^{4-} \mathrm{CE}-15 \mathrm{~V}$, and (d) $[\Delta(5,5,5)-$ $5 \mathrm{H}] 2 \mathrm{AB}^{5-} \mathrm{CE}-15 \mathrm{~V}$.

the precursor (calculated $m / z$ 457) are observed in very low abundances in both spectra. The abundances of the product ions relative to the precursor ion are significantly greater for CSA $[\Delta(5,5,5) \mathrm{PZ}-5 \mathrm{H}]^{5-}$ than for CSC $[\Delta(5,5,5) \mathrm{PZ}-5 \mathrm{H}]^{5-}$, indicating that the same trend in ion abundances is observed as for underivatized CS oligosaccharides [23] and 2AB derivatized oligosaccharides. Figure $5 \mathrm{~d}$ plots the abundances relative to the precursor ion of the product ion generated from $[\Delta(5,5,5) \mathrm{PZ}$ - 


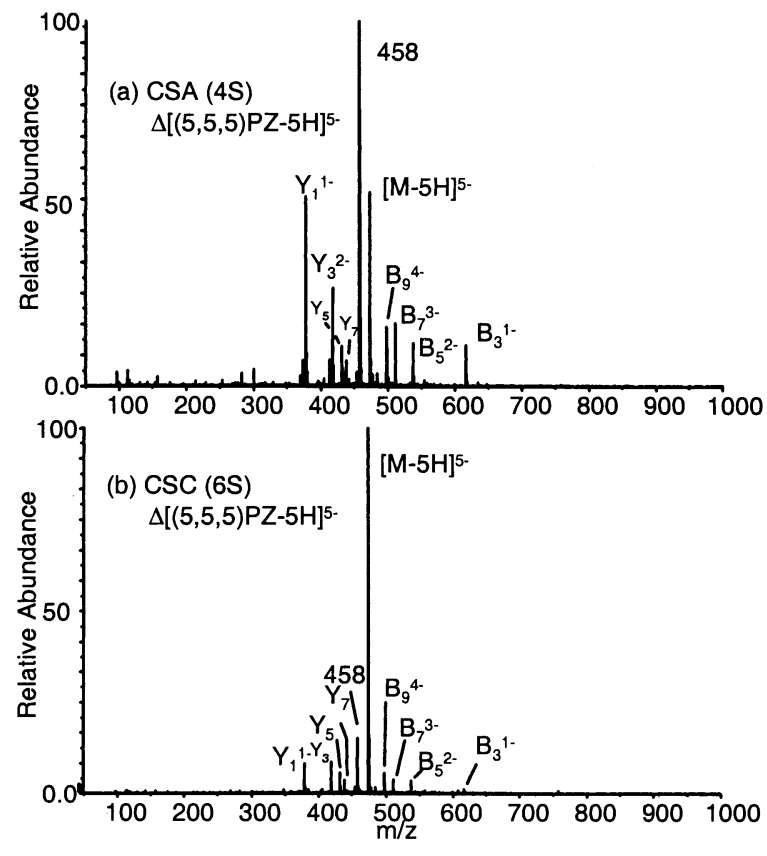

(c) $B_{m}$ CID fragment ions

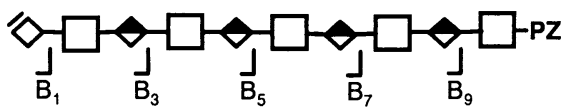

(d) Percent total ion abundances for $\mathrm{B}_{\mathrm{m}}$ ions

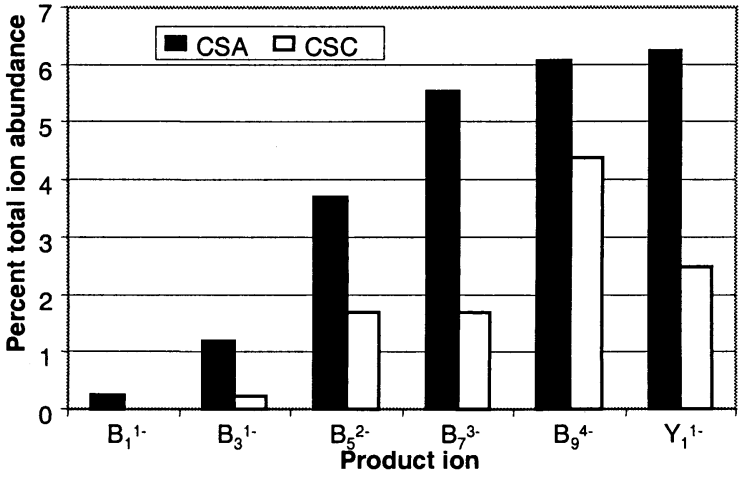

Figure 5. Q-oTOF tandem mass spectra at $-15 \mathrm{~V}$ collision energy of $[\Delta(5,5,5) \mathrm{PZ}-5 \mathrm{H}]^{5-}$ derived from (a) CSA and (b) CSC. The $\mathrm{B}_{\mathrm{m}}$ ions are shown in (c) and (d) and represent the percent total ion abundances for glycosidic bond product ions generated from the two structures. The symbol definitions are given in Figure 3.

$5 \mathrm{H}]^{5-}$ derived from CSA and CSC, respectively, in bar graph form. As observed in Figure 4, the relative abundances of ions produced by glycosidic bond cleavage reach their maximum values close to the reducing terminus. All $\mathrm{B}_{\mathrm{m}}$ product ions are more abundant for the CSA $[\Delta(5,5,5) \mathrm{PZ}-5 \mathrm{H}]^{5-}$, indicating that glycosidic bonds adjacent to 4 -sulfated GalNAc are cleaved more readily than are those adjacent to 6-sulfated GalNAc. The observation that ions corresponding to $\mathrm{Y}_{1}^{1-}$ and $\mathrm{B}_{9}^{4-}$ are more abundant for the CSA- than for CSC-derived oligosaccharide is significant in the light of those made for the tandem mass spectrum of $\triangle$ Di6S-PZ (Figure 2e). Although the evident open-ringed structure for the $\triangle$ Di6S-PZ was detrimental to differentiation of sulfation position, this is observed not to be a problem for the reducing end of oligosaccharides.

As stated above, derivatization has the dual benefits of providing a chromophore and eliminating the problem of overlapping charge states observed at $m / z 458$ for underivatized precursor ions. Derivatization may not be desirable for some applications, especially those for which there may not be enough sample to provide a strong ion signal after sample workup. It is possible to conduct CID experiments for higher charge states for CS oligosaccharides (see Figure 1), and Figure 6 compares $B_{m}$ and $Y_{n}$ ion abundances obtained by CID of $[\Delta(6,6,6)-7 \mathrm{H}]^{7-}$ ions derived from CSA and CSC, respectively. As observed with ions at $m / z 458, \mathrm{~B}_{\mathrm{m}}$ ions are consistently higher in abundance for the 4-sulfated than the 6-sulfated oligosaccharides. In contrast to the results on $m / z 458$, the $Y_{n}$ ion abundances are also reflective of the position of GalNAc sulfation. Assuming that the (a) $\mathrm{B}_{\mathrm{m}}$ ion abundances

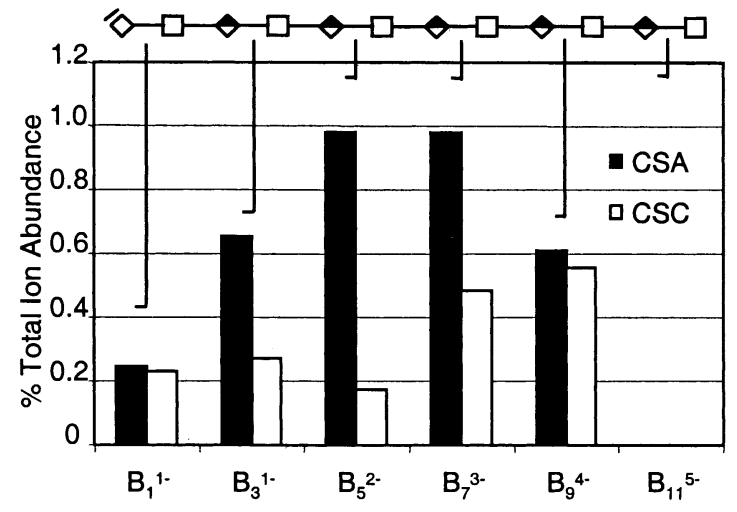

(b) $Y_{n}$ ion abundances

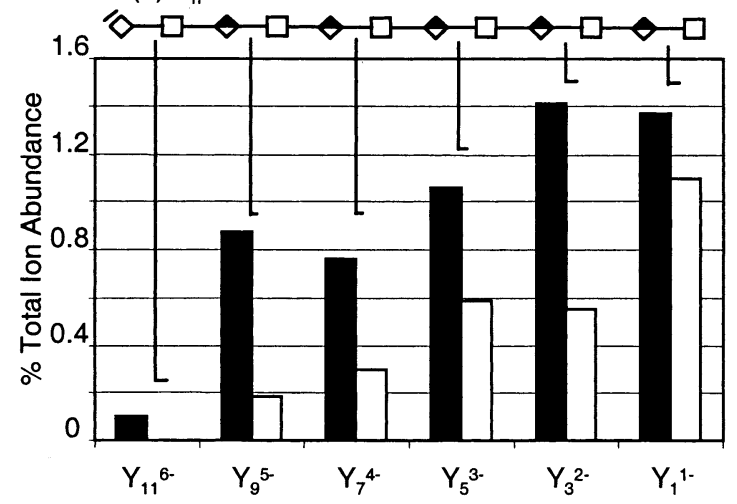

Figure 6. $B_{m}$ and $Y_{n}$ ion abundances for CID of $[\Delta(6,6,6)-7 \mathrm{H}]^{7-}$ derived from CSA and CSC, respectively, acquired using $-12.5 \mathrm{~V}$ collision energy. The symbol definitions are given in Figure 3. 
(a) Fragment ion diagram

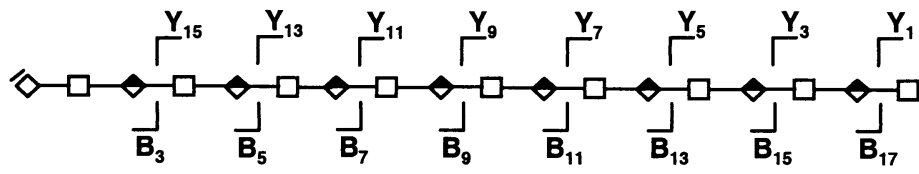

(b) Full range tandem mass spectrum with precursor ion shown in inset

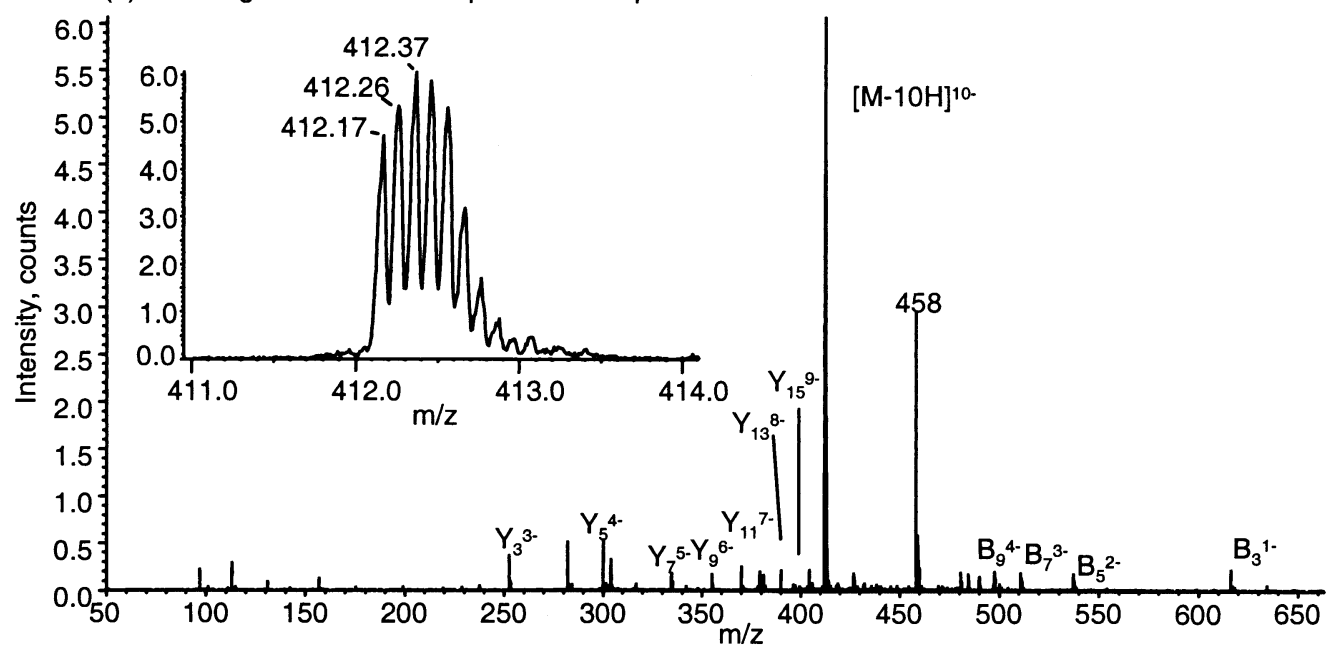

(c) Magnification of expanded mass range showing $B_{m}$ ions

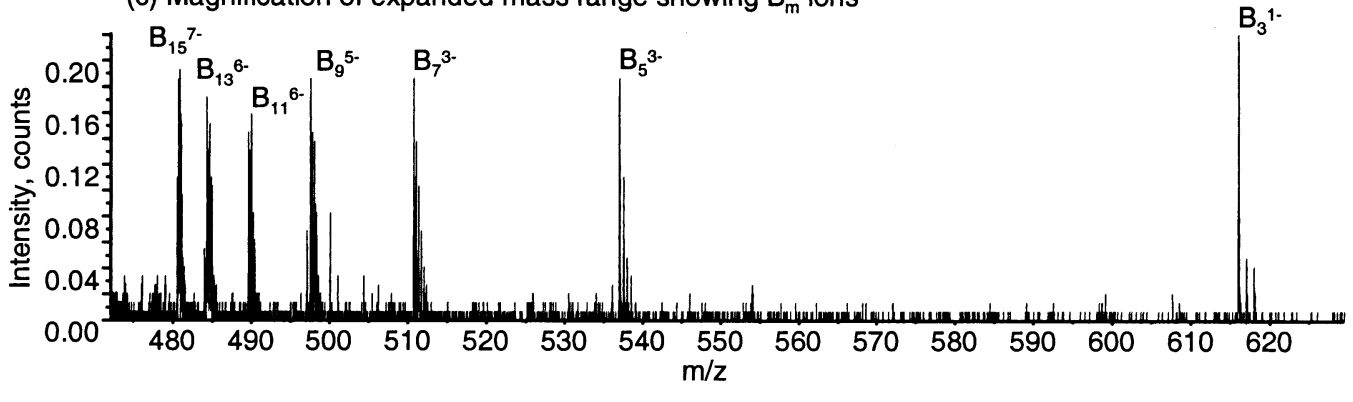

Figure 7. Q-oTOF tandem mass spectrum of CSA $[\Delta(9,9,9)-10 \mathrm{H}]^{10-}$ acquired using $12.5 \mathrm{~V}$ collision energy. The symbol definitions are given in Figure 3.

glycosidic bond fragment ion abundances reflect the position of sulfation of the neighboring GalNAc residues, the CID spectra provide information on five of the six sulfation sites. There appears to be greater information value in the product ion profiles generated from the higher charge state precursor ions.

The high density of charge on CS ions renders their fragmentation characteristics sharply different from those of peptides of similar molecular weight. Figure 7 shows CID data acquired on a CS $[\Delta(9,9,9)-10 \mathrm{H}]^{10-}$, neutral mass 4131.6. As the inset shows, the precursor ion is cleanly isolated and the isotopic cluster well resolved. The collision energy was kept low so that the precursor ion remained abundant, minimizing the extent of formation of internal fragment ions $\left(\mathrm{m} / \mathrm{z} 458^{1-}\right)$. Odd numbered $B_{m}$ ions from $B_{3}$ to $B_{15}$ are observed and $Y_{n}$ ions from $Y_{1}$ to $Y_{15}$. A peptide of similar size typically produces an incomplete series of $b_{n}$ and $y_{n}$ ions resulting from cleavage of only the most labile bonds, typically those involving Asp and Pro residues [46]. The fact that one charge is present on each sulfate group of the CS oligosaccharides is likely to cause glycosidic bond strain, resulting in similar labilities for the odd numbered glycosidic bonds in the molecule.

Dermatan sulfate (DS) is a CS variant in which a major fraction of GlcA residues have been epimerized to IdoA and may be substituted with sulfate [4]. Although, as with positional sulfation isomers, the masses of glycosidic bond cleavage ions will not differentiate uronic acid epimers, the position of epimerization is likely to influence the stabilities of glycosidic and/or ring bonds, as reflected by product ion abundances. This is supported by NMR studies on GAGs in which it is shown that IdoA residues confer conformational flexibility on the molecule [47, 48]. The degree of flexibility is likely to influence the extent to which collision energy is dispersed through vibrational or rotational channels or through bond cleavage [49].

Quadrupole ion trap CID data obtained from $[\Delta(3,3,3)-3 \mathrm{H}]^{3-}$ ions derived from CSA (4-sulfated, GlcA, Figure 8a) CSB (4-sulfated, IdoA, Figure 8b) and CSC (6-sulfated, GlcA, Figure 8c) are compared. All 

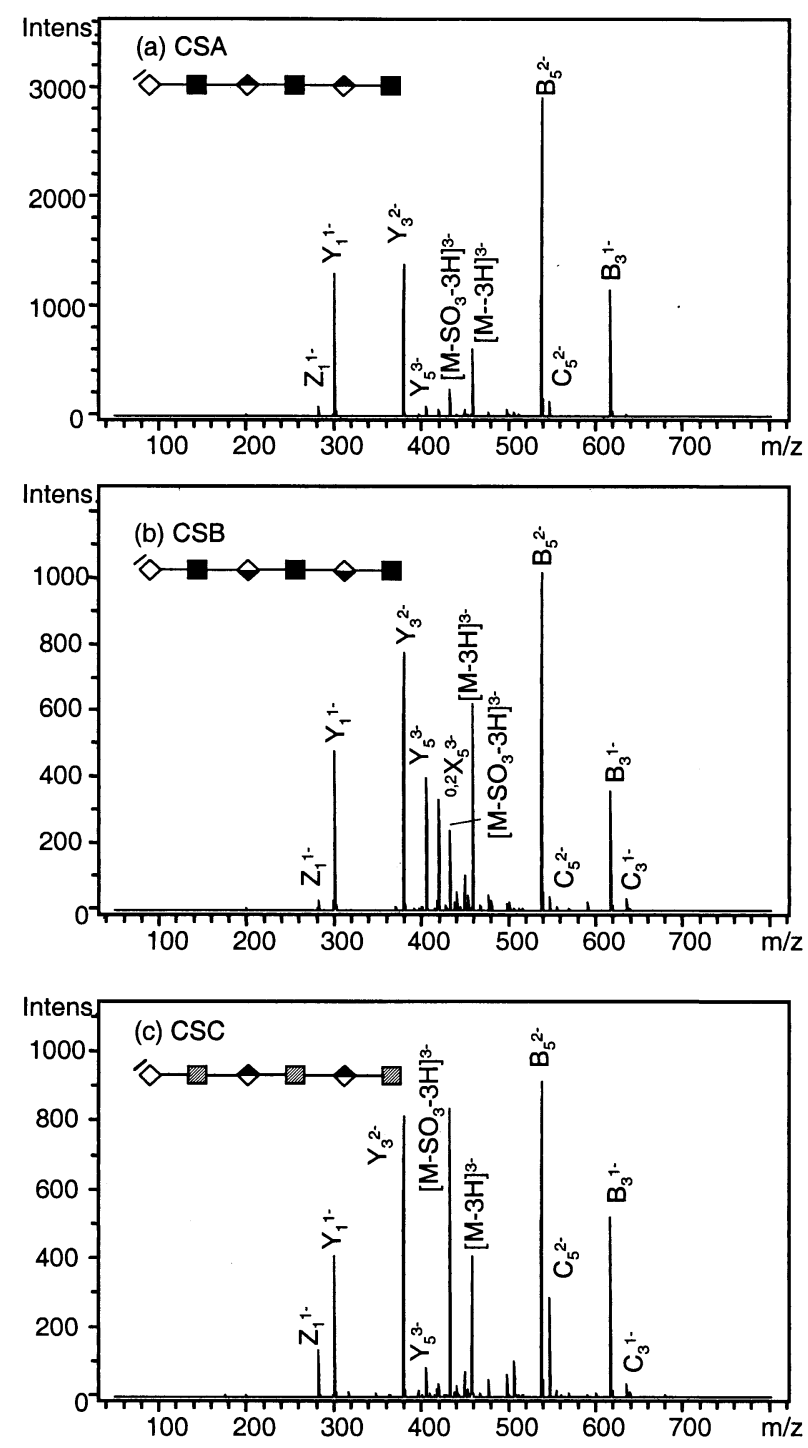

Figure 8. Comparison of CID profiles of $[\Delta(3,3,3)-3 \mathrm{H}]^{3-}$ derived from (a) CSA, (b) CSB, and (c) CSC. See Figure 9 for the fragment ion diagram. The symbol definitions are given in Figure 3.

three mass spectra display abundant $\mathrm{Y}_{1}^{1-}, \mathrm{Y}_{3}^{2-}, \mathrm{B}_{3}^{1-}$ and $\mathrm{B}_{5}^{2-}$ ions. The ions corresponding to $\mathrm{Y}_{5}^{3-}$ and ${ }^{0,2} \mathrm{X}_{5}^{3-}$ are significantly more abundant in the CID profile of CSB $[\Delta(3,3,3)-3 \mathrm{H}]^{3-}$ than for the isomers derived from CSA or CSC, consistent with the conclusion that the formation of these ions is affected by the position of uronic acid epimerization. In order to further examine this phenomenon, binary mixtures of hexasaccharides were prepared and CID product ion mass spectra were acquired. Figure 9a shows the percent total ion abundances for a series of CSA:CSB mixture ratios, varied from pure CSA to pure CSB. For this plot, the abundances of all ions in each mass spectrum were summed and the abundance of each ion expressed as a percent of the total. The experiment was repeated using Figure $9 \mathrm{~b}$ CSB:CSC (Figure 8b) and CSC:CSA (Figure 8c) mixtures. As shown in Figure 9a and $\mathrm{C}$, the abundances of $\mathrm{B}_{5}^{2-}, \mathrm{B}_{3}^{1-}$, and $\mathrm{Y}_{1}^{1-}$ vary directly with the fraction of CSA (a) CSA:CSB

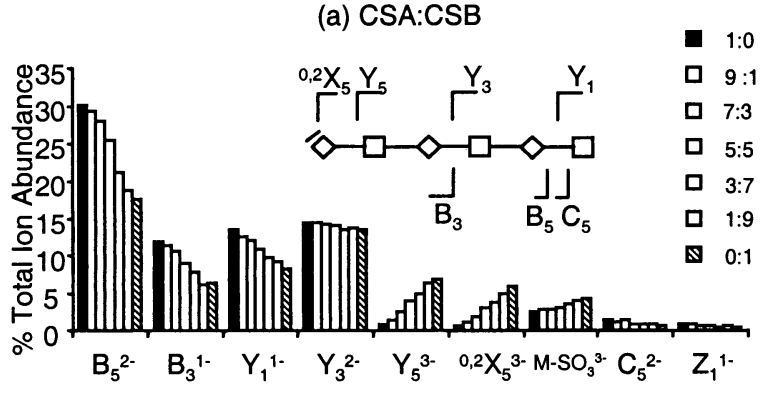

(b) CSC:CSB

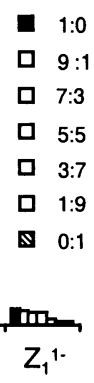

(c) CSC:CSA

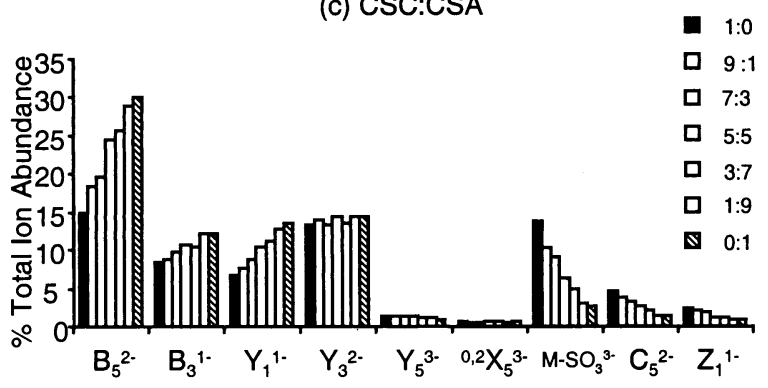

Figure 9. Percent total ion abundances for CID of $[\Delta(3,3,3)-3 \mathrm{H}]^{3-}$ ions derived from mixtures of (a) CSA:CSB, (b) CSC:CSB, and (c) CSC:CSA. CID spectra were acquired for 1:0, 9:1, 7:3, 5:5, 3:7, 1:9, $0: 1$ for each pair of oligosaccharides. The symbol definitions are given in Figure 3.

$[\Delta(3,3,3)-3 \mathrm{H}]^{3-}$ in the mixture. These ions do not vary with the CSC:CSB mixture ratio, as shown in Figure 9b, indicating that these ions reflect the presence of CSA structures, (GlcA-GalNAc-4-sulfate). The $\mathrm{C}_{5}^{2-}$ and $\mathrm{Z}_{1}^{1-}$ ions, produced from cleavage of the reducing terminal glycosidic bond, vary inversely with the content of CSC in mixtures, as can been seen from Figure $9 b$ and $c$. The abundances of the $Y_{5}^{3-}$ and ${ }^{0,2} X_{5}^{3-}$ ions vary directly with the percent of CSB in the mixture, as shown in Figure $9 \mathrm{a}$ and $\mathrm{b}$.

These results are the first evidence showing that CID product ion abundances reflect epimerization positions in GAG oligosaccharides, and it is likely that this phenomenon will be of practical use to determine the epimerization states in biologically derived samples. This will entail comparing the abundances of relevant ions, such as $Y_{5}^{3-}$ and ${ }^{0,2} X_{5}^{3-}$, produced from standard oligosaccharides, i.e., those derived from CSA, CSB, and CSC, with those produced from biologically derived 
oligosaccharides. In order to fully validate this, it will be necessary to conduct further studies to show that (1) longer oligosaccharides may be analyzed and (2) that the ion abundances will produce accurate measurements. In order to establish the validity of the correlation between ion abundances and uronic acid epimerization states, it will be necessary to purify oligosaccharides and determine the uronic acid positions using another technique. This is the subject of ongoing work in the authors' laboratory.

\section{Conclusions}

Tandem mass spectrometric determination of the sequences of CS domains entails use of chondroitinase enzymes, resulting in the formation of new $\Delta$-unsaturated non-reducing termini. The original non-reducing terminus of the CS chain will be saturated, allowing it to be identified based on its unique mass. As noted above, the $\Delta$-unsaturated oligosaccharides for which the number of sulfate groups is equal to the number of disaccharide units typically produce an ion at $m / z 458$ as the most abundant in their mass spectra. These overlapping charge states at $m / z 458$ are a problem since they prohibit isolation and fragmentation of unique quasimolecular ions. In this work, two alternatives have been demonstrated to solve this problem, (1) the use of glycosylamine derivatives to shift $m / z$ values and (2) CID of higher charge states for which $\mathrm{m} / \mathrm{z}$ values are unique.

Use of glycosylamine derivatives retains the information on sulfation position in the reducing end GalNAc residue, and is therefore preferred over reduced derivatives. Both $\mathrm{AP}$ and $2 \mathrm{AB}$ have been demonstrated to be effective derivatives with respect to CID fragmentation behavior, and both have been widely used as chromophores to facilitate chromatographic detection. Although the PZ label is not a strong chromophore, the derivatization procedure can be accomplished using volatile reagents and results in favorable tandem mass spectrometric fragmentation. The use of PZ is recommended for situations when mass shift is necessary without a strong chromophore.

This work also demonstrates that CID of higher charge states produces extremely valuable information on sulfation positions. It is of significance that, for charge states in which $z=-($ number of sulfates +1$)$, the abundances of both $B_{m}$ and $Y_{n}$ ions reflect sulfation positions on GalNAc residues. The behavior observed for $m / z 458$ precursor ions $(z=$ number of sulfate groups) results in $B_{m}$ ions that reflect sulfation positions, and $Y_{n}$ ions that do not. This difference in fragmentation is likely to be due to the number of mobile protons in the precursor ion and their abilities to destabilize glycosidic bonds. For ions where not all sulfate groups are deprotonated, for which ion charge $z$ $=-($ number of sulfates -1$)$, cleavages to the reducing side of GalNAc residues are observed, as is typical for CID of HexNAc-containing oligosaccharides under most conditions. Such cleavages are known to be charge-induced [50], and are caused in this case by the mobile proton that exists when there are fewer negative charges than sulfate groups. When all sulfate groups are deprotonated, $z=$ number of sulfates, there are no mobile protons and cleavages are observed to the bonds to the non-reducing side of GalNAc residues, indicating that these are now the most labile bonds in the ions. It is likely that these bonds are destabilized by neighboring group interactions with the carboxylic acid groups of the adjacent uronic acid residues. CID of the higher charge state, in which $z=-($ number of sulfates +1$)$, results in charge localization on one of the carboxylic acid groups of the ion, in addition to the charged sulfate groups. This evidently influences the formation of $Y_{n}$ ions such that their abundances are now sensitive to the position of sulfation of neighboring GalNAc residues.

In practical terms, the information content of CID spectra is richer for the precursor ions of higher charge state. Therefore, tandem mass spectrometric studies will be most successful for ESI solvent conditions and instrument source designs that maximize the charge states. At the present time, use of solutions that contain a low concentration of ammonium hydroxide are recommended to both maximize ion charge state and minimize the extent of sodium adduction.

This work also demonstrates that positions of uronic acid epimerization are reflected by the abundances of ${ }^{0,2} X_{n}$ and $Y_{n}$ ions resulting from fragmentation of the non-reducing residue of $\Delta$-unsaturated CS/DS oligosaccharides. These results are particularly significant because they are the first evidence that GAG oligosaccharides may be completely characterized using tandem MS. It is now clear that both positional sulfation isomers and uronic acid epimers may be differentiated using CID product ion abundances. Additional work is required in order to show exactly how these observations may be used in practice. This will entail use of carefully characterized standards to prove the value of tandem mass spectra for practical analyses. This is the subject of continuing work in the authors' laboratory.

\section{Acknowledgments}

The authors acknowledge the support for this work by NIH/ NCRR Grant No. P41-RR10888 and a Glycosciences Research Award from Neose Technologies. The Esquire 3000 mass spectrometer was donated by Bruker Daltonics, Inc. Technical assistance was provided by Omar Mohammedsalih.

\section{References}

1. Aspberg, A.; Miura, R.; Bourdoulous, S.; Shimonaka, M.; Heinegard, D.; Schachner, M.; Ruoslahti, E.; Yamaguchi, Y. The C-Type Lectin Domains of Lecticans, a Family of Aggregating Chondroitin Sulfate Proteoglycans, Bind Tenascin-R by Protein-Protein Interactions Independent of Carbohydrate Moiety. Proc. Natl. Acad. Sci. U.S.A. 1997, 94, 10116-10121. 
2. Iozzo, R. V. The Biology of the Small Leucine-Rich Proteoglycans. Functional Network of Interactive Proteins. J. Biol. Chem. 1999, 274, 18843-18846.

3. Bernfield, M.; Gotte, M.; Park, P. W.; Reizes, O.; Fitzgerald, M. L.; Lincecum, J.; Zako, M. Functions of Cell Surface Heparan Sulfate Proteoglycans. Annu. Rev. Biochem. 1999, 68, 729-777.

4. Trowbridge, J. M.; Gallo, R. L. Dermatan Sulfate: New Functions from an Old Glycosaminoglycan. Glycobiology 2002, 12, 117R-125R.

5. Cheng, F.; Heinegard, D.; Malmstrom, A.; Schmidtchen, A.; Yoshida, K.; Fransson, L. A. Patterns of Uronosyl Epimerization and 4-/6-O-Sulphation in Chondroitin/Dermatan Sulphate from Decorin and Biglycan of Various Bovine Tissues. Glycobiology 1994, 4, 685-696.

6. Karamanos, N. K.; Vanky, P.; Syrokou, A.; Hjerpe, A. Identity of Dermatan and Chondroitin Sequences in Dermatan Sulfate Chains Determined by Using Fragmentation with Chondroitinases and Ion-Pair High-Performance Liquid Chromatography. Anal. Biochem. 1995, 225, 220-230.

7. Kawashima, H.; Hirose, M.; Hirose, J.; Nagakubo, D.; Plaas, A. H.; Miyasaka, M. Binding of a Large Chondroitin Sulfate/ Dermatan Sulfate Proteoglycan, Versican, to L-Selectin, PSelectin, and Cd44. J. Biol. Chem. 2000, 275, 35448-35456.

8. Trowbridge, J. M.; Rudisill, J. A.; Ron, D.; Gallo, R. L. Dermatan Sulfate Binds and Potentiates Activity of Keratinocyte Growth Factor (Fgf-7). J. Biol. Chem. 2002, 277, 42815-42820.

9. Chai, W.; Beeson, J. G.; Lawson, A. M. The Structural Motif in Chondroitin Sulfate for Adhesion of Plasmodium falciparumInfected Erythrocytes Comprises Disaccharide Units of 4-OSulfated and Non-SulfatedN-Acetylgalactosamine Linked to Glucuronic Acid. J. Biol. Chem. 2002, 277, 22438-22446.

10. Saito, A.; Munakata, H.; Satoh, K. Glyco-Western Blotting: Biotinylated Dermatan Sulfate as a Probe for the Detection of Dermatan Sulfate Binding Proteins Using Western Blotting. Connect. Tissue Res. 2002, 43, 1-7.

11. Calabro, A.; Benavides, M.; Tammi, M.; Hascall, V. C.; Midura, R. J. Microanalysis of Enzyme Digests of Hyaluronan and Chondroitin/Dermatan Sulfate by Fluorophore-Assisted Carbohydrate Electrophoresis (Face). Glycobiology 2000, 10, 273281.

12. Calabro, A.; Hascall, V. C.; Midura, R. J. Adaptation of Face Methodology for Microanalysis of Total Hyaluronan and Chondroitin Sulfate Composition from Cartilage. Glycobiology 2000, 10, 283-293.

13. Calabro, A.; Midura, R.; Wang, A.; West, L.; Plaas, A.; Hascall, V. C. Fluorophore-Assisted Carbohydrate Electrophoresis (Face) of Glycosaminoglycans. Osteoarthritis Cartilage 2001 Suppl A, S16-, 9, S22.

14. Plaas, A. H.; West, L. A.; Thonar, E. J.; Karcioglu, Z. A.; Smith, C. J.; Klintworth, G. K.; Hascall, V. C. Altered Fine Structures of Corneal and Skeletal Keratan Sulfate and Chondroitin/ Dermatan Sulfate in Macular Corneal Dystrophy. J. Biol. Chem. 2001, 276, 39788-39796.

15. Shinmei, M.; Miyauchi, S.; Machida, A.; Miyazaki, K. Quantitation of Chondroitin 4-Sulfate and Chondroitin 6-Sulfate in Pathologic Joint Fluid. Arthritis Rheum. 1992, 35, 1304-1308.

16. Hazell, P. K.; Dent, C.; Fairclough, J. A.; Bayliss, M. T.; Hardingham, T. E. Changes in Glycosaminoglycan Epitope Levels in Knee Joint Fluid Following Injury. Arthritis Rheum. 1995, 38, 953-959.

17. Belcher, C.; Yaqub, R.; Fawthrop, F.; Bayliss, M.; Doherty, M. Synovial Fluid Chondroitin and Keratan Sulphate Epitopes, Glycosaminoglycans, and Hyaluronan in Arthritic and Normal Knees. Ann. Rheum. Dis. 1997, 56, 299-307.

18. Plaas, A. H.; Wong-Palms, S.; Roughley, P. J.; Midura, R. J.; Hascall, V. C. Chemical and Immunological Assay of the
Nonreducing Terminal Residues of Chondroitin Sulfate from Human Aggrecan. J. Biol. Chem. 1997, 272, 20603-20610.

19. West, L. A.; Roughley, P.; Nelson, F. R.; Plaas, A. H. Sulphation Heterogeneity in the Trisaccharide (GalNAcS $\beta 1$, $4 \mathrm{GlcA} \beta 1$, 3GalNAcS) Isolated from the Non-Reducing Terminal of Human Aggrecan Chondroitin Sulphate. Biochem. J. 1999, 342, 223-229.

20. Carr, S. A.; Reinhold, V. N. Structural Characterization of Sulfated Glycosaminoglycans by Fast Atom Bombardment Mass Spectrometry: Application to Chondroitin Sulfate. J. Carbohydr. Chem. 1984, 3, 381-401.

21. Reinhold, V. N.; Carr, S. A.; Green, B. N.; Petitou, M.; Choay, J.; Sinay, P. Structural Characterization of Sulfated Glycosaminoglycans by Fast Atom Bombardment Mass Spectrometry: Application to Heparin Fragments Prepared by Chemical Synthesis. Carbohydr. Res. 1987, 161, 305-313.

22. Ii, T.; Kubota, M.; Hirano, T.; Ohashi, M.; Yoshida, K.; Suzuki, S. FAB Cid-MS/MS Characterization of Tetrasaccharide Triand Tetrasulfate Derived from the Antigenic Determinant Recognized by the Anti-Chondroitin Sulfate Monoclonal Antibody Mo-225. Glycoconj. J. 1995, 12, 282-289.

23. Zaia, J.; McClellan, J. E.; Costello, C. E. Tandem Mass Spectrometric Determination of the $4 \mathrm{~S} / 6 \mathrm{~S}$ Sulfation Sequence in Chondroitin Sulfate Oligosaccharides. Anal. Chem. 2001, 73, 6030-6039.

24. McClellan, J. M.; Costello, C. E.; O'Connor, P. B.; Zaia, J. Influence of Charge State on Product Ion Mass Spectra and the Determination of 4S/6S Sulfation Sequence of Chondroitin Sulfate Oligosaccharides. Anal. Chem. 2002, 74, 3760-3771.

25. Lamb, D. J.; Wang, H. M.; Mallis, L. M.; Linhardt, R. J. Negative Ion Fast-Atom Bombardment Tandem Mass Spectrometry to Determine Sulfate and Linkage Position in Glycosaminoglycan Derived Disaccharides. J. Am. Soc. Mass Spectrom. 1992, 3, 797-803.

26. Desaire, H.; Leary, J. Detection and Quantification of the Sulfated Disaccharides in Chondoritin Sulfate by Electrospray Tandem Mass Spectrometry. J. Am. Soc. Mass Spectrom. 2000, 11, 916-920.

27. Zaia, J.; Costello, C. E. Compositional Analysis of Glycosaminoglycans by Electrospray Mass Spectrometry. Anal. Chem. 2001, 73, 233-239.

28. Desaire, H.; Sirich, T. L.; Leary, J. A. Evidence of Block and Randomly Sequenced Chondroitin Polysaccharides: Sequential Enzymatic Digestion and Quantification Using Ion Trap Tandem Mass Spectrometry. Anal. Chem. 2001, 73, 3513-3520.

29. Her, G. R.; Santikarn, S.; Reinhold, V. N.; Williams, J. C. Simplified Approach to HPLC Precolumn Fluorescent Labeling of Carbohydrates: N-(2-Pyridyl)-Glycosylamines. J. Carbohydr. Chem. 1987, 6, 129-139.

30. Kett, W. C.; Batley, M.; Redmond, J. W. Heterocyclic Derivatives of Sugars: An NMR Study of the Formation of 1-Glycosyl-3,5-Dimethyl-1- $h$-Pyrozoles from Hydrazones. Carbohydr. Res. 1997, 299, 129-141.

31. Wilm, M. S.; Mann, M. Electrospray and Taylor-Cone Theory, Dole's Beam of Macromolecules at Last? Int. J. Mass Spectrom. Ion Processes 1994, 136, 167-180.

32. Saitoh, H.; Takagaki, K.; Majima, M.; Nakamura, T.; Matsuki, A.; Kasai, M.; Narita, H.; Endo, M. Enzymic Reconstruction of Glycosaminoglycan Oligosaccharide Chains Using the Transglycosylation Reaction of Bovine Testicular Hyaluronidase. J. Biol. Chem. 1995, 270, 3741-3747.

33. Takagaki, K.; Nakamura, T.; Izumi, J.; Saitoh, H.; Endo, M.; Kojima, K.; Kato, I.; Majima, M. Characterization of Hydrolysis and Transglycosylation by Testicular Hyaluronidase Using Ion-Spray Mass Spectrometry. Biochemistry 1994, 33, 65036507. 
34. Wang, W. T. LeDonne, N. C., Jr.;; Ackerman, B.; Sweeley, C. C. Structural Characterization of Oligosaccharides by High-Performance Liquid Chromatography, Fast-Atom BombardmentMass Spectrometry, and Exoglycosidase Digestion. Anal. Biochem. 1984, 141, 366-381.

35. Carr, S. A.; Reinhold, V. N.; Green, B. N.; Hass, J. R. Enhancement of Structural Information in FAB Ionized Carbohydrate Samples by Neutral Gas Collision. Biomed. Mass Spectrom. 1985, 12, 288-295.

36. Gillece-Castro, B. L.; Burlingame, A. L. Oligosaccharide Characterization with High-Energy Collision-Induced Dissociation Mass Spectrometry. Methods Enzymol. 1990, 193, 689-712.

37. Poulter, L.; Burlingame, A. L. Desorption Mass Spectrometry of Oligosaccharides Coupled with Hydrophobic Chromophores. Methods Enzymol. 1990, 193, 661-689.

38. Harvey, D. J. Electrospray Mass Spectrometry and Fragmentation of $N$-Linked Carbohydrates Derivatized at the Reducing Terminus. J. Am. Soc. Mass Spectrom. 2000, 11, 900-915.

39. Ojala, W. H.; Ostman, J. M.; Ojala, C. R. Schiff Bases or Glycosylamines: Crystal and Molecular Structures of Four Derivatives of D-Mannose. Carbohydr. Res. 2000, 326, 104-112.

40. Li, D. T.; Her, G. R. Structural Analysis of ChromophoreLabeled Disaccharides and Oligosaccharides by Electrospray Ionization Mass Spectrometry and High-Performance Liquid Chromatography/Electrospray Ionization Mass Spectrometry. J. Mass Spectrom. 1998, 33, 644-652.

41. Li, D. T.; Sheen, J. F.; Her, G. R. Structural Analysis of Chromophore-Labeled Disaccharides by Capillary Electrophoresis Tandem Mass Spectrometry Using Ion Trap Mass Spectrometry. J. Am. Soc. Mass Spectrom. 2000, 11, 292-300.

42. Okamoto, M.; Takahashi, K.; Doi, T.; Takimoto, Y. HighSensitivity Detection and Postsource Decay of 2-Aminopyridine-Derivatized Oligosaccharides with Matrix-Assisted Laser
Desorption/Ionization Mass Spectrometry. Anal. Chem. 1997, 69, 2919-2926.

43. Egge, H.; Dell, A. Von; Nicolai, H. Fucose Containing Oligosaccharides from Human Milk. I. Separation and Identification of New Constituents. Arch. Biochem. Biophys. 1983, 224, 235253.

44. Egge, H.; Peter-Katalinc, J. Fast Atom Bombardment Mass Spectrometry for Structural Elucidation of Glycoconjugates. Mass Spectrom. Rev. 1987, 6, 331-393.

45. Domon, B.; Costello, C. E. A Systematic Nomenclature for Carbohydrate Fragmentations in FAB-MS/MS Spectra of Glycoconjugates. Glycoconj. J. 1988, 5, 397-409.

46. Yu, W.; Vath, J. E.; Huberty, M. C.; Martin, S. A. Identification of the Facile Gas-Phase Cleavage of the Asp-Pro and Asp- Xxx Peptide Bonds in Matrix-Assisted Laser Desorption Time-ofFlight Mass Spectrometry. Anal. Chem. 1993, 65, 3015-3023.

47. Casu, B.; Petitou, M.; Provasoli, M.; Sinay, P. Conformational Flexibility: A New Concept for Explaining Binding and Biological Properties of Iduronic Acid-Containing Glycosaminoglycans. Trends Biochem. Sci. 1988, 13, 221-225.

48. Venkataraman, G.; Sasisekharan, V.; Cooney, C. L.; Langer, R.; Sasisekharan, R. A Stereochemical Approach to Pyranose Ring Flexibility: Its Implications for the Conformation of Dermatan Sulfate. Proc. Natl. Acad. Sci. U.S.A. 1994, 91, 6171-6175.

49. Mendonca, S.; Cole, R. B.; Zhu, J. H.; Cai, Y.; French, A. D.; Johnson, G. P.; Laine, R. A. Incremented Alkyl Derivatives Enhance Collision Induced Glycosidic Bond Cleavage in Mass Spectrometry of Disaccharides. J. Am. Soc. Mass Spectrom. 2003, 14, 63-78.

50. Hofmeister, G. E.; Zhou, Z.; Leary, J. A. Linkage Position Determination in Lithium-Cationized Disaccharides-Tandem Mass-Spectrometry and Semiempirical Calculations. J. Am. Chem. Soc. 1991, 113, 5964-5970. 